\title{
Alternation in the Fusion Complex during Constant Pacing of Sustained Ventricular Tachycardia
}

\author{
Masaomi Chinushi, M.D., Yoshifusa Auzawa, M.D., \\ Yoriko Kusano, M.D., Hitoshi Kitazawa, M.D., \\ Takefumi Mryajima, M.D., and Akira ShiBata, M.D.
}

\begin{abstract}
SUMMaRY
In a patient with sustained ventricular tachycardia (VT), we observed two different conduction times through the reentry circuit at the critical paced cycle length. The cycle length of the VT was $420 \mathrm{msec}$ and overdrive pacing initially performed at a paced cycle length of $400 \mathrm{msec}$ and repeated at decrements of $10 \mathrm{msec}$ until the VT was interrupted at a paced cycle length of $320 \mathrm{msec}$. During rapid pacing, constant fusion and progressive fusion were confirmed. The first post-pacing return cycle was identical to each paced cycle length. The conduction time between the stimulus artifact and the orthodromically captured electrogram at the left ventricle was constant at $350 \mathrm{msec}$ in each paced cycle length. However, only at a pacing cycle length of $360 \mathrm{msec}$ two conduction times were alternatively observed, one of $350 \mathrm{msec}$ and the other of $365 \mathrm{msec}$. When the conduction time changed from $350 \mathrm{msec}$ to $365 \mathrm{msec}$, morphological alternation both in the surface QRS complex and in the orthodromically captured electrogram was evident. Dual slow pathways or a single slow pathway with plural exits from the reentry circuit is a likely mechanism of the alternation. (Jpn Heart J 34: 227-234, 1993.)
\end{abstract}

\section{Key Words:}

Ventricular tachycardia Dual pathways Slow conducting pathway Entrainment

$7 \mathrm{HE}$ conductive properties of the atrioventricular (AV) node and the accessory pathway are relatively well known, ${ }^{1)-4)}$ and dual pathways have been demonstrated as the cause of reentry in the AV node. ${ }^{4)-6)}$

In ventricular tachycardia $\left(V^{\prime}\right)$, resetting by a single extrastimulus ${ }^{7), 8)}$ or transient entrainment ${ }^{9), 10)}$ might be used to disclose the conductive characteristic of the slow conduction zone, but data concerning the electrophysiologic properties of reentry circuits in human ventricular tachycardia have been recently accumulating.

Recently, we observed an alternation both in the surface QRS complex

From the First Department of Internal Medicine, Niigata University School of Medicine, Niigata, Japan. Mailing address: Masaomi Chinushi, M.D., First Department Internal Medicine, Niigata University School of Medicine, 1-754 Asahimachi, Niigata 951, Japan.

Received for publication September 18, 1992.

Accepted October 24, 1992. 
and in the orthodromically captured electrogram during entrainment of VT at a critical paced cycle length. Change in the time interval between the stimulus and the electrograms near the site of exit was related to such alternations. Dual slow pathways and a single slow pathway with plural exits from the reentry circuit were considered to be likely mechanisms of the alternation.

\section{Case Report}

The patient was a 66-year-old female. She developed dizziness while walking 3 months before admission and she was diagnosed as having a complete AV block (Fig. 1). She did not have symptoms suggesting inflammatory disease or ischemic heart disease.

After admission to a hospital, she underwent temporary pacing for AV block, but VT with a right bundle branch block pattern (Fig. 2) occurred during the procedure and she was referred to our hospital.
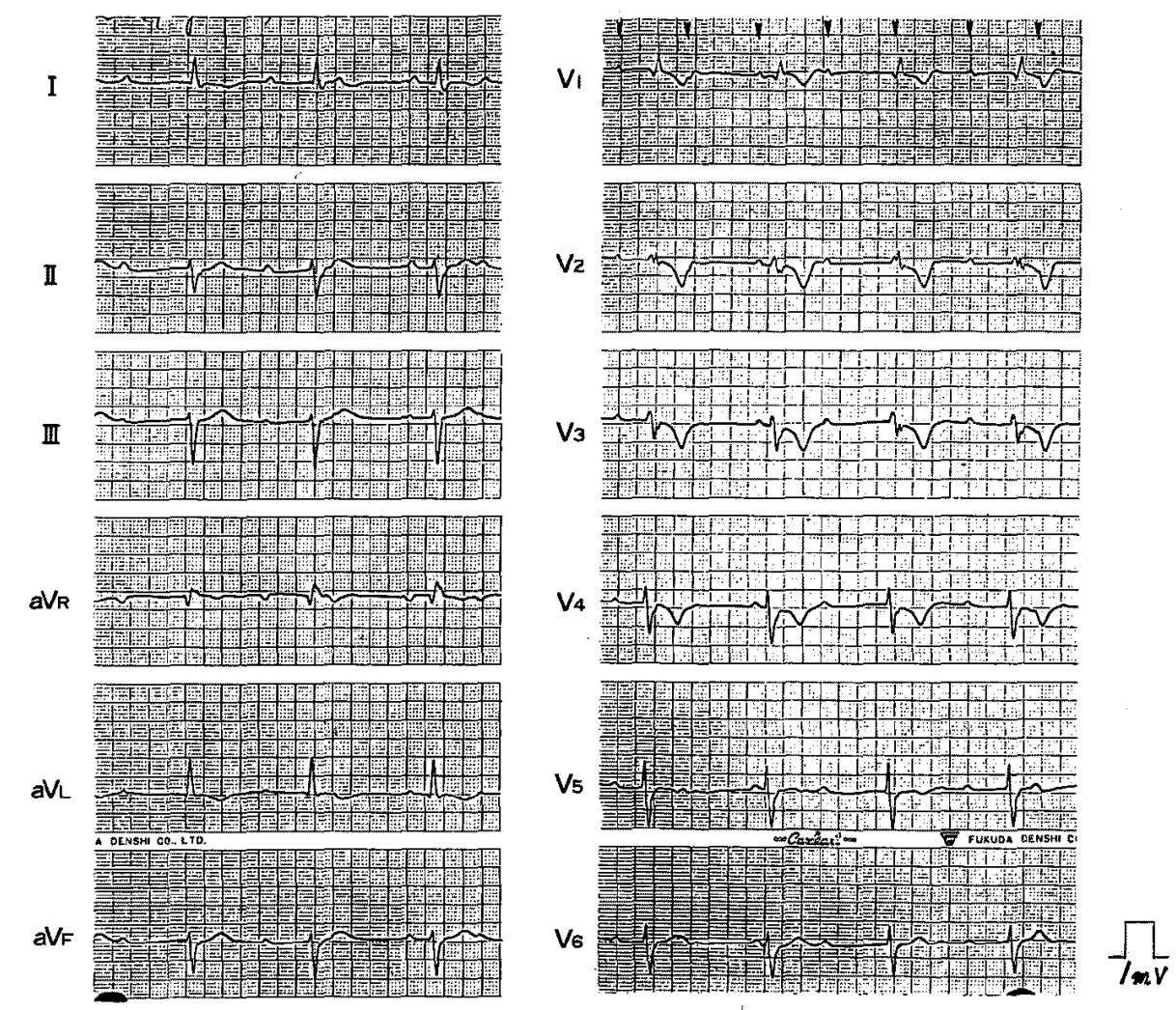

Fig. 1. Twelve-lcad electrocardiogram showing complete AV block. The rate of the QRS complex was 45 beats per minute, and that of the $P$ wave was 77 beats per minute. Arrows show the position of the $\mathrm{P}$ wave. 
On admission, she was $154 \mathrm{~cm}$ in height and weighed $57.0 \mathrm{~kg}$. The physical examination was non-contributory. The hematological and serological examinations showed no abnormalities. Her blood chemistry was also normal. The chest $\mathrm{x}$-ray showed a mildly enlarged heart but no pulmonary congestion.

Her clectrocardiogram showed a complete dissociation between the $\mathbf{P}$ wave and the QRS complex (Fig. 1). The QT interval was $0.48 \mathrm{sec}$.

The two-dimensional echocardiogram showed reduced wall motion in the apical portion of the intraventricular septum. M-mode echocardiogram showed a dilated right ventricle, $39 \mathrm{~mm}$ in end-diastolic dimension. Mild mitral and pulmonary regurgitation was observed by Doppler echocardingram. The coronary angiograms showed normal vessels.

After obtaining informed consent from her and her family, the electrophysiologic study was performed in the nonsedated and postabsorptive state. Three $6 \mathrm{~F}$ quadripolar catheters with interelectrode distances of $5 \mathrm{~mm}$ were positioned against the apex of the right ventricle, at the His-bundle electrogram recording area and at the left ventricle, under fluoroscopic guidance. The stimulation was performed using electrodes 1 (distal tip) and 3, and the intracardiac electrogram from the pacing site was recorded using electrodes 2 and 4 . Otherwise, the local electrogram was recorded using the two distal electrodes, 1 and 2.

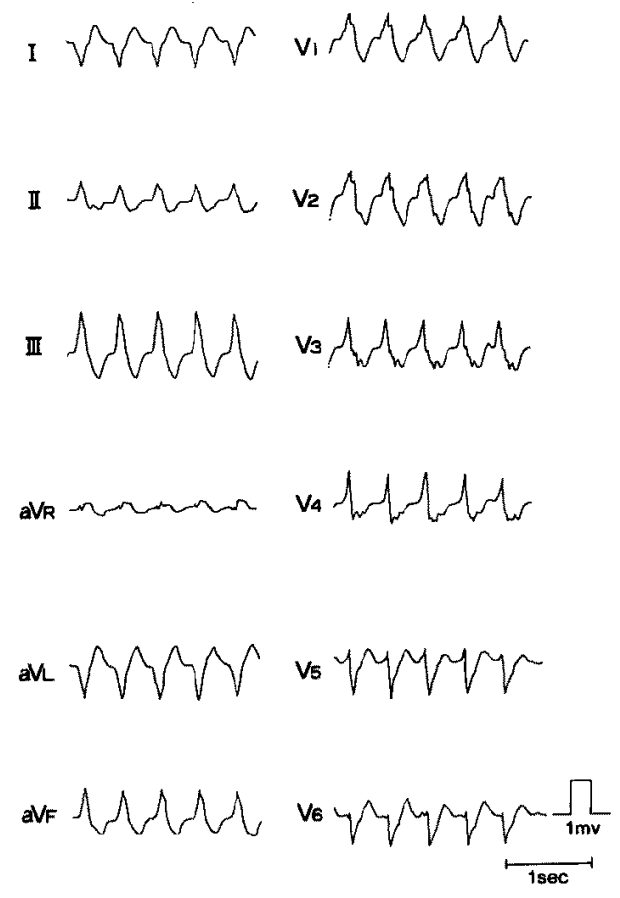

Fig. 2. Twelve-lead electrocardiogram showing ventricular tachycardia. The VT shows a right bundle branch block pattern with a cycle length of $420 \mathrm{msec}$. 
The heart was stimulated at twice diastolic threshold with a $2 \mathrm{msec}$ rectangular pulse by a programmable stimulator (Fukuda Denshi Co., Cardiac Stimulator BC02). A standard stimulation protocol was used for the induction of VT. ${ }^{(1), 12)}$ Intracardiac electrograms were recorded on an ink-jet recorder (Siemens Elema Co. Ltd., Mingograf 7) with three surface leads, I, II, and $V_{1}$, at a paper speed of $100 \mathrm{~mm} / \mathrm{sec}$. The band-pass filter was set at 50 to $300 \mathrm{~Hz}$.

In the drug-free state, VT with the same configuration as that of clinical VT was induced by double extrastimuli from the apex of the right ventricle. The cycle length of VT was 420 msec. Endocardial activation was mapped extensively, and the earliest site of activation was determined at the lateral wall of the left ventricle. The local electrogram at the site was $10 \mathrm{msec}$ before the onset of the QRS complex.

Then, rapid pacings were performed from the apex of the right ventricle to entrain tachycardia starting at a cycle length 20 msec less than the cycle length of VT and after decrements of $10 \mathrm{msec}$ until VT was interrupted at a paced

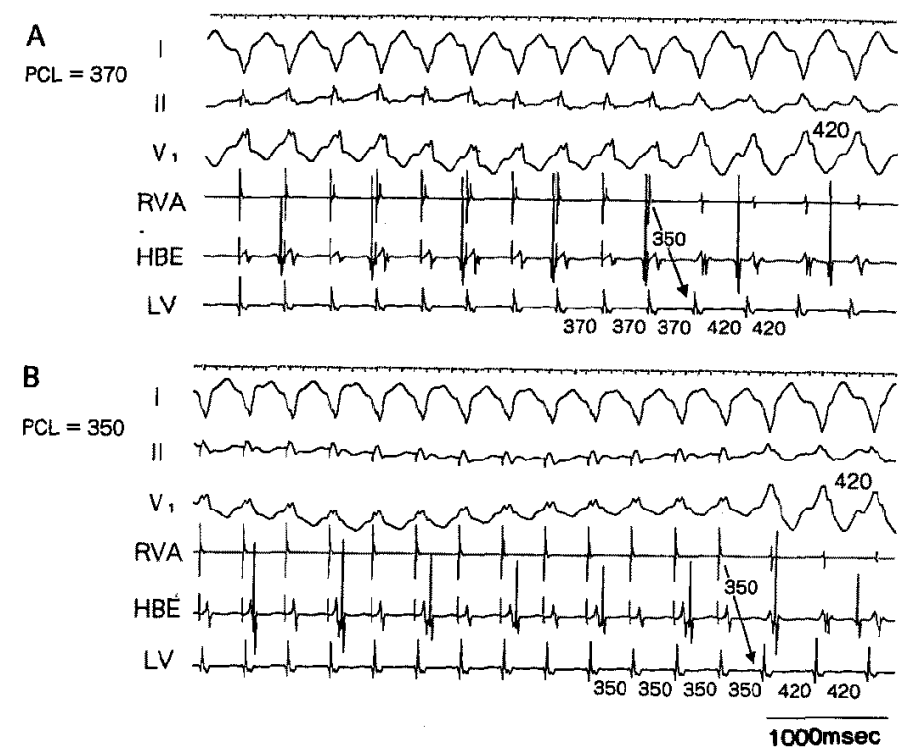

Fig. 3. Overdrive pacing during the VT,

The VT cycle length was $420 \mathrm{msec}$. Overdrive pacing was performed at cycle lengths of $370 \mathrm{msec}$ (A) and $350 \mathrm{msec}$ (B). Constant fusion was observed in the QRS complex and constant fusion with different degrees at different paced cycle lengths was also confirmed. The interval from the stimulus to the entrained local electrogram at the left ventricle was constant: $350 \mathrm{msec}$, and the local electrogram showed the same morphology at each paced cycle length. The first post-pacing return cycle was identical to each paced cycle length.

$\mathrm{RVA}=$ right ventricular apex; $\mathrm{HBE}=$ the tricuspid ring in the His-bundle area; $\mathrm{LV}=$ lateral wall of the left ventricle; $\mathrm{PCL}=$ paced cycle length. 


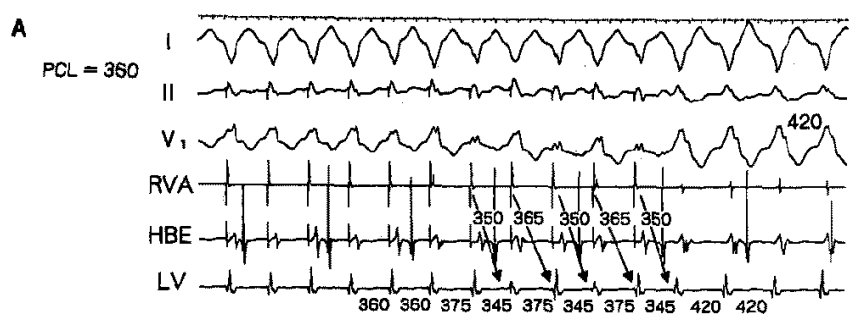

Fig. 4. Overdrive pacing during VT.

Overdrive pacing was performed at a cycle length of $360 \mathrm{msec}$ during the VT (A). During the last part of the pacing, two conduction times from the stimulus artifact to local electrogram at the left ventricle were altematively observed. As the conduction time changed, the local electrogram at the left ventricle also showed slight alternation in the morphology and in the cycle length: one was $375 \mathrm{msec}$ and the other was $345 \mathrm{msec}$. At the same time, the QRS complex on the surface electrogram changed in morphology. During the pacing in the escape rhythm (B), the interval from the stimulus artifact to the local electrogram at the left ventricle was $80 \mathrm{msec}$. Abbreviations are the same as in Fig. 3.

cycle length of $320 \mathrm{msec}$. During rapid pacing, constant fusion and constant fusion with different degrees at different paced cycle lengths were confirmed ${ }^{13), 14)}$ (Fig. 3). The first post-pacing return cycle was identical to each paced cycle length. ${ }^{14 j}$ These findings fulfilled the criteria of transient entrainment established by earlier workers. ${ }^{13)-15)}$

As reported earlier ${ }^{10)}$ the conduction time through the reentry circuit was measured as the time interval from the stimulus (apex of the right ventricle) to the orthodromically captured electrogram (lateral wall of the left ventricle) near the site of exit from the slow conduction zone. As the paced cycle length decreased from 400 to $370 \mathrm{msec}$ and from 350 to $320 \mathrm{msec}$, the conduction time was fixed at $350 \mathrm{msec}$. The fusion QRS complex was stable during the pacings (Fig. 3).

At the intermediate paced cycle length of $360 \mathrm{msec}$, the conduction time was found to alternate between $350 \mathrm{msec}$ and $365 \mathrm{msec}$. The alternation in conduction time was accompanied by a slight change in the morphology of the local electrogram recorded at the lateral wall of the left ventricle (Fig. 4A). Alternation in the QRS morphology on the surface electrogram was also observed during the alternation of the conduction times. We did not add extrastimulation during the VT. During the escape rhythm, the conduction time from the stimulus artifact to the lateral wall of the left ventricle was $80 \mathrm{msec}$ (Fig. 4B). 


\section{Discussion}

Recently, electrophysiologic data concerning the slow conduction zone have been accumulating. ${ }^{7-10), 16,17)}$ The evaluation of the conductive properties of the slow conduction zone has been performed by two approaches. One is the resetting of the VT by extrastimulation ${ }^{7,8,8,16)}$ and the other is the use of transient entrainment of VT with rapid pacing. . $^{9,10,17)}$

In the present case, we measured the conduction time as the time interval between the stimulus and the orthodromically captured electrogram at the left ventricle near the site of exit from the reentry circuit. Obviously, additional time is involved in this conduction time which is required for the wave fronts to propagate between the pacing site and the entrance of the reentry circuit. The conduction time was constant, $350 \mathrm{msec}$ at each cycle length, except for the pacing at a cycle length of $360 \mathrm{msec}$. At this critical cycle length, the conduction times alternated between 350 and $365 \mathrm{msec}$.

There are several possible explanations for the alternation of the conduction time: (1) There are alternating pathways within the reentry circuit. (2) A latency at the pacing site or two conducting pathways in the tissue intervening between the pacing site and the entrance of the reentry circuit. (3) There are two entrances or exits in the reentry circuit. ${ }^{18)}$ (4) A slight shift of the catheter position might cause a change in the conduction time and morphology; this possibility was felt to be unlikely because this alternation occurred only at the critical paced cycle length.

When the conduction time changed from 350 to $365 \mathrm{msec}$, the local electrogram at the left ventricle showed a slight change in morphology. This finding suggests a change in the activation sequence from the éxit of the reentry circuit. The antidromically propagating wave front did not seem to relate to the change in the morphology, because a stimulus artifact was found in the orthodromically captured electrogram at the site during the entrainment, and the conduction time from the stimulus artifact to the local electrogram at this site was $80 \mathrm{msec}$ during the escape rhythm (Fig. 4B). These findings suggested that the antidromically activating wavefront could not reach this site during the entrainment and this site was activated orthodromically. Therefore, we think that alteration in QRS morphology is a secondary phenomenon due to alternating conduction over two slow pathways or due to changing the two exits of one slow pathway from one to the other.

Although the existence of two pathways between the stimulus site and the entrance of the reentry circuit could not be excluded, the change in the morphology of the local electrogram could not be explained by this mechanism. Also, a latency at the pacing site was not observed during the entrainment. 
We were unable to determine the precise mechanism of the initiation of such an alternating conduction, and linking between two slow conducting pathways or so-called supernormal conduction ${ }^{19,20)}$ might be related to the finding. However, this phenomenon was an unusual feature seen during rapid pacing in VT, and it would be important to examine the conductive characteristics in the reentry circuit.

\section{REFERENCES}

1. Burgada P, Vanagt E, Dassen WR, Gorgels AP, Bar FW, Wellens HIJ: Atrioventricular nodal tachycardia with and without discontinuous anterograde and retrograde atrioventricular nodal conduction curves: a reappraisal of the dual pathway concept. Eur Heart J 1: 399, 1980

2. Critelli $G$, Gallagher JJ, Monda V, Coltorti F, Scherillo M, Rossi L: Anatomic and electrophysiologic substrate of the permanent form of junctional reciprocating tachycardia. J Am Coll Cardiol 4: 601, 1984

3. Morady F, Kadish AH, Schmaltz S, Rosenheck S, Summitt J: Effects of resting vagal tone on accessory atrioventricular connections. Circulation 81: 86, 1990

4. Rosen KM, Mehta A, Miller RA: Demonstration of dual atrioventricular node pathways in man. Am J Cardiol 33: 291, 1974

5. Atie J, Brugada P, Brugada J, Smeets JLRM, Cruz FES, Peres A, Duque M, Wellens HU: Longitudinal dissociation of atrioventricular accessory pathways. J Am Coll Cardiol 17: 161, 1991

6. Denes P, Wu D, Amat-y-Leon F, Dhingra R, Wyndham CR, Rosen KM; The determinations of atrioventricular nodal reentry with premature atrial stimulation in patients with dual A-V nodal pathways. Circulation 56: 253, 1977

7. Almendral JM, Stamato NJ, Rosenthal ME, Marchlinski FE, Miller JM, Josephson ME: Resetting response patterns during sustained ventricular tachycardia. Circulation 74: 722, 1988

8. Gottlieb CD, Rosenthal ME, Stamato NJ, Frame LH, Lesh MD, Miller JM, Josephson ME: A quantitative evaluation of refractoriness within a reentrant circuit during ventricular tachycardia. Relation to termination. Circulation 82: 1289, 1990

9. Kay GN, Epstein AE, Plumb VJ: Preferential effect of procainamide on the reentrant circuit of ventricular tachycardia. J Am Coll Cardiol 14: 382, 1989

10. Aizawa $\mathrm{Y}$, Ebe $\mathrm{K}$, Satoh M, Shibata A: Conduction through the reentrant circuit in recurrent sustained ventricular tachycardia evaluated by transient entrainment. Jpn Circ J 54: 1113, 1990

11. Wellens HJJ, Duren DR, Lie KI: Observations on mechanisms of ventricular tachycardia in man. Circulation 54: 237, 1976

12. Josephson ME, Horowitz LN, Farshidi A, Kastor JA: Recurrent sustained ventricular tachycardia. I. Mechanism. Circulation 57: 431, 1978

13. Waldo AL, Henthorn RW: Use of transient entrainment during ventricular tachycardia to localize a critical area in the reentry circuit for ablation. PACE 12: 231, 1989

14. Waldo AL, Henthorn RW, Plumb VJ, Maclean WAH: Demonstration of the mechanism of transient entrainment and interuption of ventricular tachycardia with rapid atrial pacing. J Am Coll Cardsol 3: 422,1984

15. Okumura K, Olshansky B, Henthorn RW, Epstein AE, Plumb VJ, Waldo AL: Demonstration of the presence of slow conduction during sustained ventricular tachycardia in man: use of entrainment of the tachycardia. Circulation 75: 369, 1987

16. Almendral JM, Rosenthal ME, Stamato NJ, Marchlinski FE, Buxton AE, Frame LH, Miller JM, Josephson ME: Analysis of the resetting phenomenon in sustained uniform ventricular tachycardia: incidence and relation to termination. J Am Coll Cardiol 8: 294, 1986

17. Aizawa $Y$, Niwano S, Chinushi M, Tamura M, Kusano Y, Miyajima T, Kitazawa H, Shibata A: The 
incidence and mechanism of interruption of the reentrant ventricular tachycardia with rapid ventricular pacing. Circulation 85: 589, 1992

18. Ebe K, Aizawa Y, Satoh M, Funazaki T, Myajima S, Niwano S, Tamura M, Shibata A, Miyamura H, Eguchi S: Ventricular tachycardia with two possible exits from one reentrant circuit. Jpn Circ J 54: 214, 1990

19. Igarashi M, Ayabe T: Quantitative study of the supernormal phase of ventricular excitability in man. Am J Cardiol 36: 292, 1975

20. Chinushi M, Aizawa Y, Funazaki T, Tamura M, Shibata A: Frequency and output dependent change in conduction over slow pathways in a patient with sustained ventricular tachycardia unrelated to coronary artery disease. PACE 15: 756, 1992 